The Geneva Papers on Risk and Insurance, 20 (No. 76, July 1995), 454-462

\title{
The Limits to Insurability from a Law and Economics Perspective
}

\author{
by Michael G. Faure LL.M.*
}

\section{Introduction}

There has been a great deal of commotion in the insurance world of late. No one can deny that insurers are being confronted with growing liability in all kinds of domains. Examples which spring to mind are Dutch court judgments, for example on asbestos and DES, but also developments in legislation both in the Netherlands and at the European level. Alongside these changes in the law, which increase the chance of liability, there are a number of other reasons why it is realistic to assume that there will be greater recourse to holding perpetrators liable in the near future, and thus a greater claim on their insurers. First of all, one can point to a change in consumers' behaviour as regards claims. Consumers are more articulate, existing relationships as between employer and employee are no longer an impediment to bringing a claim and, more generally speaking, the idea that anyone who suffers loss is entitled to full compensation is gaining ground in society at large. Secondly, this idea is further fostered by a tendency to privatise social security. In the past, claims on any possible liable perpetrators tended not to be invoked because the real costs of an event were spread among the community by means of social insurance. But because the social security system was in danger of becoming unaffordable, the government is increasingly withdrawing from the arena.

The upshot of this is that more is being left to employers (take the case of the privatisation of the Sickness Benefits Act), or the possibilities of recovery from liable third parties are being extended in social insurances. Thirdly, there is good reason to expect that the amount of claims will considerably increase. Traditionally, the Netherlands was a

*Michael Faure is professor of comparative and international environmental Law at the Faculty of Law of the University of Limburg. Maastricht. 
country where pain and suffering were basically not eligible for compensation, or only to a limited degree. But recent cases in which compensation for pain and suffering has been awarded are clearly going in a different direction.

Although it is unlikely that we will blindly follow the American example of compensating pain and suffering, since this depends for one thing on the contingency fee system that applies in America for paying lawyers, and on the jury system, nevertheless, it would be fair to expect a general rise in the amounts claimed and awarded. All these developments are producing great concern among insurers. The voices heard a few years ago about a possible insurance crisis, are now becoming increasingly vociferous. Consequently, insurers are complaining bitterly that everything is going dramatically wrong and that the growing liability is no longer insurable.

The question I wish to address in this paper is to what extent this claim is justified. In answering this question one has to make a big distinction as regards the situation in which an insurer today can see a growing liability moving in his direction and can adjust his policy conditions accordingly. Such changes, apart from a few exceptions, do not constitute all too grave a threat to insurers, I believe, because they can calculate the risk beforehand and can command a corresponding premium and build up a reserve. It only becomes really problematical when the rules of the game are changed halfway through the match. The biggest problems, consequently, are those being encountered by insurers who are being faced with exorbitant environmental liability claims, which they could never have foreseen, under policies that were concluded in the fifties. Now one could, of course, concentrate on the second situation and ask the question as to how an insurer can cover himself policywise against mid-term changes, by stipulating for instance that a change to the liability will entail cover being limited or excluded. These questions have been studied by Hartlief/Spier and Wansink (see the literature references at the end of the article). But I am particularly interested in the first question, namely, whether growing liability in itself, if this is to some extent predictable, can give rise to uninsurability. The key thread running through my discourse is that this need not necessarily be the case as long as the sacred laws of insurance economics are respected, namely that the insurer demands a premium that is equal to the probability (p) of an event with a damage (d) occurring, together with a surplus for administrative charges (loading costs). Moreover, he should properly spread his risk in accordance with the law of large numbers; he has to avoid adverse selection and control the moral hazard.

\section{Predictable?}

When one listens to insurers lamenting growing liability, these are usually cases in which, on the ground of existing policies, they can observe changes in the law. Such changes then either involve greater liability (an increase in the (p) in other words) or an increase in the damage (d). If such changes are predictable beforehand a competitive insurance market will in principle be prepared to cope with the accompanying rising demand for insurance provided there is sufficient capacity. This is why I think it is important in the debate on the limits to insurability to keep very clearly in mind whether we are talking about predictable changes, for which a commensurate premium can be commanded, or unpredictable changes. The latter will in many cases of course result in uninsurability because such changes are diametrically opposed to the essential principles of insurance, 
namely asking a premium for a calculated risk. It would, however, be more interesting to dwell briefly here on the phenomenon that really could lead to the uninsurability of a certain risk from the point of view of insurance economics.

\section{Uncontrollable moral hazard}

One phenomenon that in terms of insurance economics really can result in uninsurability is the moral hazard. This is the phenomenon familiar to all insurers that the behaviour of an insured party changes simply because of the fact of him having full insurance. Since the risk for him has been eliminated, for example in the form of liability insurance, he no longer has the same incentive that he had when he was fully exposed to the risk. The problem for an insurer is that because of the insured party's retrospective change in behaviour, the (p) starts to rise so that the premium will be too low. If this moral hazard cannot be properly contained, a risk does indeed become uninsurable. Not only is it then dangerous for the insurer to enter into a contract with the insured party, but any insurance at all would, socially speaking, be undesirable because the risk of accident will rise as a result of the availability of insurance. The fact that liability insurance was banned in many Western European countries up until the nineteenth century and in the former Soviet Union until quite recently, is evidence of the fact that we are not talking here of imaginary risks. The uninsurability arising from an unverifiable moral hazard remains if an insurer is unable to check the behaviour of the insured party (for example, because of insufficient information) or does not want to check for certain reasons. Unfortunately, there are quite a few examples of this latter. Van den Bergh and myself carried out research some years ago into liability insurance for the liberal professions in Belgium. To our surprise we found that, after reported events, there was scarcely any differentiation made between good and bad risks, neither beforehand nor afterwards. In the case of medical liability, there was only the desperate remedy of excluding entirely a physician who had made a great many claims. Asked for the reason for such limited differentiation, the insurer replied that it was exceptionally difficult for him to check up on the behaviour of a practitioner of the liberal professions, like a physician or a lawyer. Many professions of this kind are still regarded as eminently respectable, which means that an insurer would appear to have a certain antipathy to a detailed check. Another example is quoted in a study by Adams and Finsinger in which they point out that as a result of the way premiums are regulated in Germany every insurer is obliged to calculate a profit margin. This guaranteed profit margin, combined with the absence of any proper competition in the insurance market, entailed, according to Adams and Finsinger, that insurers no longer had any incentive to check properly the moral hazard vis-à-vis parties with motor vehicle insurance, for example by penalising bad behaviour and rewarding good behaviour. This, too, can result in an insurmountable moral hazard, certainly from a social point of view, which tends in the direction of uninsurability. They suggest that the structure of the insurance market in Germany has resulted in higher road fatalities than in comparable countries where there is more competition and no regulation of premium, like the United Kingdom.

\section{Checks are possible}

It needs not always happen this way. There are, of course, techniques which allow insurers to check the moral hazard. First of all, the insurer can always partially expose the 
insured party to risk (for example by introducing an excess, deductible or offset or by including a ceiling for coverage). The latter in particular is extremely useful, viewed in the light of checking the moral hazard. It will, after all, entail that the insured party himself always remains exposed to risk and therefore has an incentive to take prevention action. To my mind, thought is too frequently given in the debate on the scale of cover solely to the potential capacity of an insurer. With a view to checking the moral hazard, however, it would seem important always to limit cover, even if this is not necessary in terms of capacity. The second, and really the most ideal way of checking the moral hazard, is to verify the behaviour of the individual insured party by means of modified policy conditions and to adjust the premium for the risk constituted by the individual in question. In a case of this kind, if the policy conditions are adapted optimally, the insured will, in principle, have the same incentive to take prevention action as he had when he was not insured. This means that the insurer insists on necessary preventive mechanisms, for avoiding occupational accidents for instance, by means of the policy conditions. Once again, it is clear that the insurer is going to be playing an extremely important social role. The drawback is that an individual check by the insurer does, of course, cost a great deal of money. Whether this will always be possible will depend, for one thing, on the value of the policy. Large companies with a substantial portfolio will probably be able to obtain a tailor-made policy, but for average consumers off-the-peg policies will be inevitable. But even a certain degree of standardisation need not stand in the way of differentiation. After all insurers can create certain separate risk categories, depending on the individual risk constituted by the various insured parties. Differentiation of this kind can allow for a proper check on the moral hazard since the premium and the policy conditions will be reasonably adjusted to the risk constituted by the insured party in question if there is proper differentiation. Differentiation therefore would seem to be the appropriate response to the moral hazard. Insurers' inability to properly identify the diverse risks could indeed lead to uninsurability.

\section{Adverse selection}

The same remedy can actually be prescribed for another phenomenon which may jeopardise efficient insurance, namely the phenomenon referred to as adverse selection. The phenomenon of adverse selection entails that an insurer, because he has no proper information about the risk constituted by the individual insured party, is unable to make a proper differentiation in premiums. This will in turn mean that insurance is relatively too expensive for the good risks, leaving the insurer with the bad risks and hence uninsurability. This, of course, needs some explanation. The basic problem is the phenomenon of 'asymmetric information' spotted by Akerlof, the fact that information is not always equally distributed among the parties. This is also the case with insurance, and the interesting thing is that the insurer actually has to be regarded as the weak party.It is the insured party, after all, who possesses all the information regarding the individual risk he constitutes and the insurer who lacks it. For the insurer, the art is precisely to get hold of that information by means of adapted techniques. Such asymmetric information may trigger off the process of adverse selection because a good risk is no longer rewarded by an insurer in the form of a lower premium, for instance, since the insurer simply cannot recognise it. In the long run, this will have the effect of the good risks leaving the risk group and the average premium rising accordingly, and this process being repeated until the insurer is ultimately left with only the bad risks. This adverse selection phenomenon is connected with 
important basic principles of insurance, including the idea that insurance is based on the spreading of risk but at the same time on grouping the comparable risks. The spreading of risks therefore is certainly not diametrically opposed to differentiation of risks. The risk is only spread among members of a group which constitute more or less the same risk.

Adverse selection also has to do with another familiar phenomenon that insurance is always comparatively more attractive to the bad risks. It is precisely this adverse selection phenomenon which is the reason why the Dutch insurers in 1955 agreed by binding decision to cease insuring damage by flood. Even in the present debate surrounding possible insurance for flood damage, this still plays a major role. There is fairly great risk that it is precisely the owners whose homes are below water level and on the winter dikes who will ask for flood insurance. Nevertheless, I wonder whether the adverse selection problem in this connection is entirely convincing. It seems to me perfectly possible to create a risk group of insured parties who are all of them potentially at risk of becoming a victim of flooding (e.g. those people who live in Noord Holland, Zeeland and Limburg). Naturally, uncertainty as to who will be affected always remains. An insurer, for example, would be unwise to insure all houses in Borgharen (a village close to the river) which are located on the winter dike. On the other hand, it would seem to be much less risky if he could spread that risk among residents of homes in Borgharen, Noord Holland and Friesland.

Whatever the case may be, unverifiable adverse selection can in reality lead to uninsurability. This was demonstrated by Priest who asserted that the insurance crisis in the United States in the eighties was attributable to adverse selection problems. Priest also indicated what the appropriate remedy was for adverse selection, namely adequate risk differentiation: defining the risk group as closely as possible and fixing the premium accordingly. It is only through proper risk differentiation that good risks can be properly rewarded in the form of lower premiums and in turn prevented from leaving the risk group.

\section{The amount of the damage?}

Reading some legal literature and listening occasionally to the responses of insurers themselves, one finds that they primarily relate uninsurability to the nominal amount of the damage. Extremely high amounts they allege are uninsurable. I have the impression that people are frequently being far too imprecise here. Solely the fact that compensation for damage awarded is rising, does not constitute, in my view, any serious problem for insurers, provided these amounts can be estimated beforehand and borne in mind when determining the premium and setting aside reserves. Determination of the premium is based on the product of (p) $x(d)$. Ideally, an insurer prefers a risk with a high frequency and on a relatively low scale. This makes the calculation easier and the risk more limited. The problem, however, is that the probability is sometimes difficult to estimate, especially with the so-called catastrophe risks, because there are no adequate statistics available while, moreover, the scale of the damage, if an actual event does occur, can be spectacularly high. This is naturally the fear of every insurer. Insurers themselves, too, have an antipathy to risks that are so high that should they occur they jeopardise their own existence. From this it follows that the scale of the damage does indeed play a role in determining insurability. But does this justify the conclusion that events for which the scale of the damage is high are, by definition, uninsurable? Of course not. The rule is simply that an insurer himself is bound by his own capacity and he himself will also spread his risk. Hence 
there are many techniques that have been developed for coverage in cases where the scale of damage is high. Think of reinsurance, co-insurance, pooling of risks. Thanks to these techniques, insurers have proved capable of covering risks which potentially entail astronomical amounts, such as space accidents.

Even if an earthquake were to occur in San Francisco on the scale of the one in 1906, this would produce an insured sum of $\$ 39$ billion. I am quoting this to show that the fact of the scale of damage being high does in itself not say a lot about insurability. Naturally, a market will ultimately have to indicate the capacity that it is prepared to make available for a particular risk and, in the case of extremely high risks, this maximum may be lower than the actual scale of the damage. This is undoubtedly the case with nuclear insurance. The rule here is that insurability is ultimately decided by the market and by the insurers themselves. Someone once wrote 'Insurability is the willingness of insurers to provide coverage' and that is, of course, the way it is. From this it follows that insurers, I think, should be more wary of saying that risks are uninsurable when the scale of the damage is extremely high. After all there are enough insurance techniques to provide coverage for high risks and ultimately nobody is asking any insurer to cover extremely high risks for one hundred per cent. An insurer can always limit his contribution, bearing in mind the available capacity. This also entails to my mind, however, that the government, in assessing any insurability, should not be persuaded all too readily by the opinions of insurers. Insurability, after all, remains a subjective concept and in many cases is very difficult to determine objectively. Hence, I think it is wrong to limit liability itself (as is increasingly being requested by all kinds of interest groups) on the strength of unlimited liability being uninsurable. This argument has little point because an insurer in essence will never provide unlimited coverage. The fact that the insurer confines the coverage to what he regards as an insurable amount, should be no reason whatsoever for the government to confine liability to that amount. On the contrary, from the point of view of checking the moral hazard it would, in fact, seem to be an excellent idea to provide insurance coverage that is less than the scale of the damage. To my surprise, I am noticing, therefore, that insurers, as their clients' advocates, would seem to be pleading for limits to liability. One might improperly remark that in the first place this is not in their interests, because growing liability creates new markets which insurers should applaud, but, on top of all this, it offers a better opportunity first and foremost of checking the moral hazard.

The demand on the part of insurers to limit a liability, however, does become understandable if they fear that they will have to pay higher, unforeseen amounts for which no corresponding premium could be commanded nor any reserve set aside under old policies which cannot be immediately cancelled. But given the hypothesis that an insurer can anticipate a high scale of damage beforehand, it would seem to me to have little point to advocate limiting liability.

\section{Growing liability}

Up to now I have said that I think the risks of uninsurability are not as bad as we think. I have primarily endeavoured to indicate that the risks do not lie where people tend to want to see them, namely in the high scale of the damage, but rather in bottlenecks in terms of insurance economics, such as adverse selection and moral hazard. But does this 
mean that the maelstrom in which our liability law finds itself, according to Spier, is no reason at all for insurers to worry? My argument is that extension of liability need not lead to uninsurability if it is foreseeable beforehand. Amendments and supplements to liability law have been going on, after all, since the sixties and insurers have always managed to adapt themselves accordingly. A good example of this, of course, is the adjustment that took place after the implementation of the European directive on product liability in the Netherlands. This undoubtedly entailed an extension to producers' liability. In some cases, therefore, insurers adapted the policy conditions to the new situation. But there was no major problem because it was directly stipulated in the directive itself that the new regime was solely applicable to products that were brought onto the market after the national amending legislation had come into force. There was no retroactive force, in other words. Now it is true to say that in recent years developments in case law and legislation have moved fast. The main question to be asked here is whether an insurer is entitled to adjust his policy conditions, limit coverage or exclude coverage should such an unexpected amendment to liability law occur. It is this question which Wansink, Hartlief and Spier have addressed. Does it mean that one can categorically assert that there is no reason whatsoever to fear a liability or insurance crisis in the Netherlands?

\section{Uninsurable risks}

Unfortunately it has to be said that the trends in some cases are such that they are diametrically opposed to the essential principles of insurance economics. This is naturally the case when legislation or case law suddenly invokes liability with retroactive force or if an insured party is held liable for risks which he himself has not caused. Cases of this kind do indeed present instances of uninsurability.

Uninsurability arises if the developments in the law become so unpredictable that the estimation of a risk is totally impossible. This can happen if insurers are suddenly held liable in retrospect for risks which were not foreseeable at the time when the insurance contract was concluded and for which, therefore, no premium was commanded nor any reserve set aside. Assessment of the risk also becomes impossible if insurers are required to provide coverage for damage which may possibly have been caused by third parties as well, that is to say other parties than the one they had insured. Two examples of situations of this kind can be given. The first is when retroactive liability is accepted. This tendency was very much observable in Dutch case law regarding liability for soil clean-up where the requirement of an event being foreseeable was eliminated. But in the well-known judgments Akzo/Resins and the State/Van Wijngaarden it was decided that as a result of the relativity principle claims indeed could only be valid with retroactive force to 1 January 1975. It was only as of that date that the potential polluter could have known that the government was going to concern itself about the fate of the soil. The next step was for legislative initiatives to be taken to set aside the relativity principle in the case of soil clean-up proceedings. However, by virtue of the ultimate version of the New Soil Protection Act, a claim is nevertheless possible if the double condition is met that the perpetrator knew the serious dangers or should have known them and that with a view to these, failed to refrain from polluting acts for which he is seriously culpable. Naturally, it will depend on the interpretation of these concepts in the courts how far this liability extends for insurers. The problem remains, of course, that many insurers in the past agreed 
fairly extensive coverage on the basis of which they are now having to pay for environmental pollution also caused in the past.

A second development which makes it difficult to assess risks has to do with causal uncertainty. Increasingly, in situations where there is uncertainty as to the causal connection, the uncertainty is being attributed to the employer or producer (and, therefore, his insurer). These developments, which are based on the idea of protecting the victim are, I think, extremely dangerous for insurers.

A first example is the DES case in which, admittedly, certainty existed as to the victim and as to the fact that a number of producers had marketed a certain pharmaceutical, but uncertainty existed as to which producers had sold the product. The Netherlands Supreme Court applied the law of alternative causation which entails that DES daughters can claim full compensation from any producer whatsoever (with subsequent mutual recourse). Also in the case of the employer's liability for asbestos, the causal uncertainty was passed on to the employer. The Supreme Court decided in CYSOUW/De Schelde that the burden of proof that the fatal fibre had not been encountered during work with the employer, rested with the employer.

All these are instances of case law coming to the aid of the victim by constructions to alleviate the burden of proof. My problem is that this entails the insurer of the said employer or producer being required to compensate for damage which, on the whole, was probably never caused by the insured party. In insurance economics terms it is, of course, entirely impossible to cover a risk if, as insurer, one is deemed liable to cover not only the damage of one's own party but also the damage that may have possibly been caused by another.

\section{Some final remarks}

I have indicated in this paper that the limits to insurability in economic terms are primarily dictated by the need to control the moral hazard and the adverse selection problem. All the worrying developments in the Netherlands in the field of liability law and the privatisation of social security will undoubtedly lead to an increase in the probability and the scale of damage. But as long as these developments are reasonably foreseeable, so that an insurer can command a premium beforehand and set aside a reserve, there are no insurmountable problems. Moreover, in terms of policies, conceivable solutions exist for possible extensions to liability resulting from changes in the law in the future. It is important that a response be given both to growing liability and to the moral hazard and adverse selection by means of adequately differentiating risks. This assumes that insurers, much more than was the case to date, should endeavour to obtain adequate information on the risks constituted by their own insured parties and conduct a policy to differentiate risks accordingly.

Risk differentiation is naturally no final answer to the problem posed by growing liability. Some developments, such as retroactive liability and attribution of uncertainty as to the cause to the insured party, do really exceed the limits to insurability. In these cases it seems to me of utmost importance that insurers point out to lawyers, legislators, and judges, the detrimental consequences of such decisions in the insurance field. A great many illusions can be dispelled by providing accurate information of what can and cannot be expected from liability insurance. 


\section{BIBLIOGRAPHY}

ADAMS, M., Okonomische Analyse der Gefährdungs- und Verschuldenshaftung, Heidelberg, R. v. Decker's verlag, 1985.

AKERLOF, G., 'The Market for Lemons. Quality, Uncertainty and the Market Mechanism', Quarterly Journal of Economics, 1970, 488-500.

FAURE, M. and van den Bergh, R., 'Compulsory Insurance for Professional Liability', Geneva Papers on Risk and Insurance, 1989, 308-330.

FAURE, M. and Van den Bergh, R., 'The Impact of insurance on Civil Liability: A law economics analysis' in: The influence of Insurance on Civil Liability. Pre-recommendations published for the Vereniging voor Burgerlijke Recht, Lelystad, Vermande, 1990, 17.

FAURE, M., 'Prevention of Accidents by Efficient Liability Rules and Insurance Policies on Competitive Insurance Markets', Verzekeringsarchief 1993, 3-22.

FINSINGER, J., HAMMOND, E. and TAPP, J., Insurance: Competition or Regulation. A comparative study of the Insurance Markets in the United Kingdom and the Federal Republic of Germany, London, Institute for Fiscal Studies, 1985.

HARTLIEF, T. and SPIER, J., 'Insurance and Liability with retroactive force', Aansprakelijkheid en verzekering, 1994, 27-33.

PRIEST, G., 'The Current Insurance Crises and Modern Tort Law', Yale Law Journal, 1987, 15211590.

SHAVELL, S., 'On Moral Hazard and Insurance', Quarterly Journal of Economics, 1979, 541-562.

WANSINK, J.H., 'The DES judgment in the Perspective of Insurable Protection for Victims', Aansprakelijkheid en verzekering, 1993, 6-12.

WILS, W.P.J., 'Insurance Risk Classifications in the EC: Regulatory Outlook', Oxford Journal of Legal Studies, 1994, 449-467. 